\title{
Interactive comment on "Sea surface temperature in the Indian sector of the Southern Ocean over the Late Glacial and Holocene" by Lisa C. Orme et al.
}

\section{Anonymous Referee \#1}

Received and published: 2 April 2020

This paper presents a new high-resolution diatom based sea surface temperature reconstruction over the past $\sim 14$ ka from the modern Permanent Open Ocean Zone between the Antarctic Polar Front and winter sea ice edge in the western Indian Sector of the Southern Ocean. The high-resolution record resolves centennial- to millennial-scale climate variability that enables a detailed comparison to Antarctic ice core records. Complex processes involving reorganization of atmospheric and oceanic circulation, such as CO2 levels, Southern Westerly Winds, and AMOC, have been attributed to the in-phase variation between the marine and ice core records. Periodicities of 200-260 years were identified in the Mid-Late Holocene interval, they were related 
This paper provides a novel sea surface temperature record from an area very limited records are available, especially compared to the Atlantic and Pacific sectors of the Southern Ocean. Thus, the new data from this study augment valuable information to a more comprehensive understanding of environmental changes in the Southern Ocean. However, there are a few aspects that the authors can clarify or improve before publication.

1. Study area This part is too extensive. The text can be more concise and focused on information directly related to this study.

2. Methods (a) Age model: Line 117-122: The authors claim that the reservoir applied in the Atlantic sector of the Southern Ocean derived from comparison between 14C ages and 226Ra-in-barite ages (van Beek et al., 2002) are not reliable "because large variations of $\sim 400$ years were observed between consecutive depths", and listed studies showing relatively constant reservoir in the Southern Ocean (Hall et al., 2010; Siani et al., 2013). Regarding this statement, I hold different opinion. The 226Ra-inBarite ages are consistent and in good order in van Beek et al. (2002). The resulted large variation in calculated reservoir ages are mostly because $14 \mathrm{C}$ ages measured in different labs (Kiel \& Aarhus). The $14 \mathrm{C}$ ages from Aarhus is systematically ca. 300 years younger than those from Kiel, which lead to 300-400 years variation of reservoir changes in consecutive depth. For this reason, a mean value of ca. 1100+-210 years reservoir was taken for mid-late Holocene, and adopted to other South Atlantic cores (e.g., Xiao et al., 2016). As such, the results in van Beek et al. (2002) do not really conflict with a relatively constant reservoir during the mid-late Holocene in the South Atlantic. Besides, in Hall et al. (2010), the authors propose reservoir ages of 1144+-120 years for the mid-late Holocene in the Ross Sea sector of the Southern Ocean, similar to the results from the South Atlantic. In Siani et al. (2013), their record MD07-3088 is located at $\sim 46^{\circ} \mathrm{S}$, much north of the modern Subantarctic Front. We could expect different reservoir effect in different water masses, such as in cores south of the Polar Front and north of the Subantarctic Front. It is good that the reservoir ef-

Interactive comment

Printer-friendly version

Discussion paper 
fect applied in this paper results in a good alignment between the marine and ice core records. However, due to the lack of knowledge of precise reservoir variation through time, slight phase shifts in marine records can be attributed to age uncertainty.

(b) SST reconstruction Line 132: Do the SSTs reconstructed in this study represent true surface $(0 \mathrm{~m})$ temperatures? Because other transfer functions estimate temperatures at $10 \mathrm{~m}$ water depth (Esper et al., 2014), which could result in some difference when comparing with other records (e.g., variation amplitude).

3. Discussion (a) Line 216: cores located north of the modern APF generally show a late Holocene warming trend. The referenced cores showing late Holocene warming cited here include TN057-17 (Nielsen et al., 2004; Divine et al., 2010) from the Southern Ocean Atlantic sector close to the modern Polar Front, and MD07-3088 off Chilean margin far north of the Subantarctic Front (Siani et al., 2013). However, there are reconstructions adjacent to these two cores do not show such warming. For example, PS1654/ODP1093 close to TN057-17 do not show clear warming during the late Holocene, although the resolution is much lower in PS1654/ODP1093 in the midlate Holocene interval (Xiao et al., 2016). Further north, a mid-late Holocene cooling was inferred from ODP1098 and ODP1090 (Xiao et al., 2016). Alkenone-derived SST records off Chilean margin (including MD07-3088) also suggest a mid-late Holocene cooling which is in contrast to the MD07-3088 SST record derived from foraminifera assemblage using modern analogue technique (Lamy et al., 2010, Nat. Geosci.; Haddam et al., 2018, QSR). In general, the majority of the available records show a midlate Holocene cooling in the Southern Ocean (e.g., Bostock et al., 2013; Xiao et al., 2016). While the late Holocene SSTs reconstructed in core TN057-17 far exceeding modern temperatures (by $\sim 2^{\circ} \mathrm{C}$ ) (Nielsen et al., 2004; Divine et al., 2010) need more explanation.

(b) Line 291-293: Given the timing and synchronicity between $\mathrm{CO} 2$ increases and some of the temperature records, it is possible that $\mathrm{CO} 2$ caused much of the warming... -> How do you quantify the warming by redistribution of heat between

\section{CPD}

Interactive comment
Printer-friendly version

Discussion paper 
northern and southern hemispheres during the period of AMOC slow-down (bipolarseesaw), and the warming due to $\mathrm{CO} 2$ rise? I understand the positive feedback of CO2 increase on warming, but I do not understand how does it reach the conclusion that $\mathrm{CO} 2$ is the main driver of Southern Ocean warming just based on the synchronicity of warming and $\mathrm{CO} 2$ rise.

Interactive

(c) In chapter 5.2.2, the authors cited several references showing a weakening of SWW during the early Holocene (Fletcher and Moreno, 2011; Saunders et al., 2018). However, it needs to be mentioned that, the weakening of SWW at this time interval was north of modern Polar Front. A southward shift of the SWW was inferred during this time interval (as suggested by opal accumulation, Anderson et al., 2009; Xiao et al., 2016), which indicate the SWW in regions further south can be stronger. Such interpretation is misleading in terms of eddy transport of heat and atmospheric circulation, which occurred also in the following text. The core latitudinal band of the SWW shifts with the warming/cooling of the Southern Hemisphere.

(d) Line 310-311: ... the few high resolution SST records from the open ocean do not show a cooling (Figure 7; TN057-13PC4; TN057-17TC)... -> Do you mean a cooling event? Because TN057-13, together with many other South Atlantic cores south of the modern Polar Front, show persistent cooling after ca. 8 ka (Divine et al., 2010; Xiao et al., 2016). In fact, the SiZer analysis of SST (Fig. 5) and cold water species (Fig. 3) show many cooling episodes during the mid-late Holocene, with amplitude similar or even steeper than that around $8 \mathrm{ka}$. It may reflect millennial-scale climate variability during the mid-late Holocene, rather than linking to a single cooling event in the Northern Hemisphere.

(e) The 220-260 yrs periodicity found in the SST record needs more explanation. The authors listed a number of published records around Antarctica with similar cyclicities, that most of them were related to solar activities in their respective publications. The authors then introduced other studies linked such cyclicity to atmospheric circulation such as SAM and ENSO, and rapid climatatic events globally. This part is confusing 
as it seems related to so many processes and how exactly they work needs better elaboration.

Some minor points are as follows:

Line 34: For example during ... -> For example, during. . Younger Dryas (13.02-11.76 ka BP) -> 12.9-11.7 ka (Rasmussen et al., 2014 Quat. Sci. Rev. 106, 14-28)

Interactive

comment

Line 35: accumulate in the South Atlantic -> accumulate in the Southern Ocean causing a "bipolar seesaw" characterized by... - > causing a "bipolar seesaw" pattern characterized by...

Line 63: during the Holocene there is. . - -> during the Holocene, there is. . .

Line 71-72: extending from the Subantarctic Front in the north. . . - extending from the Polar Front in the north. . (Diekmann, 2007, Deep-Sea Res. II 54, 2350-2366)

Line 74: (Park et al., 1998) -> Park et al. (1998) is not a sea ice study. This can be replaced by more recent satellite observations of sea ice extent, such as Parkinson \& Cavalieri, 2012, The Cryosphere 6, 871-880.

Line 101-102: ....in the southwestern Indian sector of the Southern Ocean... -> To make the text more concise, this can be removed as there is an extensive description of the study region in the previous chapter.

Line 108: Neogloboquadrina pachyderma -> species name should be italic.

Line 134: Winter sea ice concentration was. . . -> abbreviation (WSIC) should be noted here

Line 173: A number of references describing environmental preferences of the species need to be mentioned before referring certain species to, e.g., PFZ species, POOZ species, and sea ice species. References can be cited are Zielinski and Gersonde, 1997, Palaeo 3; Crosta et al., 2005, Palaeo 3; Armand et al., 2005, Palaeo 3; Romero et al., 2005, Palaeo 3; Esper et al., 2010, Palaeo 3.

Printer-friendly version

Discussion paper 
Line 234: This record was constrained. . . -> The MD07-3088 record...

Line 248: warming in the COR1GC and ice core records. . . -> warming in the COR1GC and Antarctic ice core records...

Line 262: Hogg et al., 2007 -> Hogg et al., 2008

Interactive

Line 299: Reconstructions support that the SWW were weaker between 11 and $7 \mathrm{ka}$ BP... -> The authors need to mention that the weakening of SWW at this time interval was north of modern Polar Front. A southward shift of the SWW was inferred during this time interval (as suggested by opal accumulation, Anderson et al., 2009; Xiao et al., 2016), which indicate the SWW in regions further south can be stronger.

Line 303-304: This is uncertain as modern observations instead show that weaker SWW's cause reduced eddy activity and less poleward heat transport across the ACC, resulting in cooling (Hogg et al., 2007; Screen et al., 2009). -> Reference error: Hogg et al., 2008 As above, SWW did not weaken at all latitudinal bands.

Line 306-309: The duration and timing of the SST cooling observed in the COR1GC record coincides with an AMOC reduction and North Atlantic cooling associated with the 8.2 event (Ellison et al., 2006) however it has not generally been observed in records from the southern hemisphere (Alley and Ágústsdóttir, 2005). -> Modeling study by Renssen et al. (2010) suggests the upwelling of cooler NADW in the Southern Ocean could result in the drop of surface temperature between 9 and $7 \mathrm{ka}$.

Line 315: From the mid to late Holocene the high latitude insolation decreased (Divine et al., 2010) -> Unclear expression. Do you mean southern high latitude? Summer insolation increased during the mid-late Holocene in southern high latitude. Do you mean winter or spring insolation? or annual insolation? Divine et al., 2010 is not the proper reference for insolation, use Laskar et al., 2004 instead.

Line 315-316: causing the SWW's to shift northward -> coherent with the northward shift of the SWW

Printer-friendly version

Discussion paper

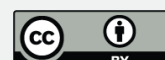


Line 317: Divine et al., 2010 -> use Laskar et al., 2004 for insolation reference

Line 317: causing the SWW's to strengthen (e.g. Saunders et al., 2018) -> as above, CPD need to mention strengthening in areas north of the modern Polar Front. It can be weakening in the south.

Line 319-320: The strengthened winds may also have increased upwelling and therefore productivity. -> south of the Polar Front, upwelling was reduced during the mid-late Holocene (Anderson et al., 2009).

Line 336: in the atmosphere may. .. -> in the atmosphere circulation

Line 356: spring insolation extending the summer season -> what does it mean?

Fig. 2: as the last age control point is at $240.9 \mathrm{~cm}(13.93 \mathrm{ka} \mathrm{BP})$, why there is a sudden increase in sedimentation at the core base, where no actual age constraint is available?

Fig. 3: I would suggest to arrange the species from left to right according to their ecological preferences in terms of temperature. For example, F. separanda, F. rhombica and T. gracilis are cold water species, which can be placed next to the sea ice species. Such arrangement will show evolution pattern of the diatom assemblage more clearly, which reflect environment changes.

Fig. 8: the opal flux record in panel (d) seems incomplete? There are breaks in the curve.

Interactive comment on Clim. Past Discuss., https://doi.org/10.5194/cp-2020-23, 2020. 